\title{
Estudo da resistência mecânica e análise térmica da resina epóxi
}

\author{
Study of mechanical resistence and thermal analysis of epoxi resin \\ Ricardo de Freitas Cabral ${ }^{*}$, Pedro Paulo Motta Barbosa Cicchelli ${ }^{\dagger}$, Cláudio Filipe de Aguiar \\ Alvarenga ${ }^{\dagger}$, Fábio Amaral Araújo ${ }^{\dagger}$, Vinícius Vicente Silva Rosa ${ }^{\dagger}$, Brunna Fialho Leite ${ }^{\dagger}$
}

Como citar esse artigo. Cabral, RF;

Cicchelli, PPM; Alvarenga, CFA; Araújo, FA; Rosa, VVS, Leite, BF. Estudo da resistência mecânica e análise térmica da resina epóxi. Revista Teccen. 2018 Jun/Dez.; 11 (2): 32-39.

\begin{abstract}
Resumo
Também conhecida como poliepóxidio, a resina epóxi é um tipo de resina plástica que quando misturada a um catalisador inicia seu processo de cura. É um polímero termorrígido, que diferentemente dos polímeros termoplásticos, não pode ser reprocessado com calor, sendo maleável apenas no momento de sua fabricação. $\mathrm{O}$ fato de não poderem ser remodelados se deve pelo motivo de que suas macromoléculas formam uma estrutura chamada reticulado que consistem em uma rede de ligações tridimensionais que se ligam em todas as direções do espaço. A resina epóxi é infusível e insolúvel em solventes orgânicos comuns, tais como hidrocarbonetos aromáticos e alifáticos. Ao final de sua polimerização apresenta grande resistência, não sendo sensível ao calor excessivo, água e ácidos. Este material é muito utilizado como cola para outros polímeros, compósitos, cerâmicos e até metais, e apresentam além destas aplicações citadas diversas aplicações na construção civil, na indústria, artesanato e na confecção de peças elétricas e eletrônicas. Neste trabalho foram confeccionados corpos de prova para avaliação de algumas propriedades da resina epóxi, por meio dos ensaios de tração, flexão, Dureza Shore D, Microscopia de luz e Microscopia Eletrônica de Varredura (MEV). Foram obtidos muitos resultados relevantes, tais como, dureza de 62,98SD (Shore D), 26MPa de tensão máxima de flexão, o seu módulo de elasticidade foi de $288,7 \mathrm{MPa}$ e a sua temperatura de transição vítrea foi de $355,60^{\circ} \mathrm{C}$.

Palavras-Chave: Resinaepóxi; Degradação térmica; Propriedades mecânicas.
\end{abstract}

\begin{abstract}
Also known as polyepoxidium, Epoxy Resin is a type of plastic resin that when mixed with a catalyst begins its healing process. It is a thermoset polymer, which, unlike thermoplastic polymers, can not be reprocessed with heat, being malleable only at the time of manufacture. The fact that they can not be remodeled is due to the fact that their macromolecules form a structure called reticulate, which is nothing more than a network of three-dimensional bonds that bind in all directions of space. Like all other polymers in this group, Epoxy Resin is infusible and insoluble in common organic solvents, such as aromatic and aliphatic hydrocarbons. At the end of its polymerization has great resistance, not being sensitive to excessive heat, water and acids. This material is widely used as glue for other polymers, composites, ceramics and even metals, but has the most and besides these applications, it has several applications in civil construction, industry, handicrafts and the manufacture of electrical and electronic parts. In this work, specimens were prepared for the evaluation of some properties of Epoxy Resin, by tensile, flexural, Shore D Hardness, Light Microscopy and Scanning Electron Microscopy (SEM) tests. Many relevant results have been obtained, such as, having average hardness values of 62.98 SD (Shore D), and $26 \mathrm{MPa}$ of maximum flexural stress, its modulus of elasticity was $288.7 \mathrm{MPa}$ and its temperature of glass transition was $355.60^{\circ} \mathrm{C}$.

Keywords: Epoxyresin; Thermal degradation; Mechanical properties.
\end{abstract}

\section{Introdução}

Resinas epoxídicas são uma forma modificada de resinas acrílicas estas últimas, tem um volumoso uso dentro da odontologia, pela existência de um elevado conteúdo de monômeros de metilmetacrilato (Menezes, Adde, Utumi, Pedron, \& Silva, 2011).

Os polímeros acrílicos apresentam propriedades distintas e diversificações em seu peso molecular, assim suas características físicas e mecânicas podem ser afetadasem função desses fatores (Morais, Mello, Souza, Ponzi, \& Revoredo, 2007).
Resinas epóxi vêm cada vez mais conquistando o seu espaço nos dias atuais devido à versatilidade de seu uso, por serem compostas basicamente de dois materiais, sendo um conhecido comoaraldite e o outrocomo catalisador (Panzera et al., 2010), facilidade de manipulação e polimerização. A resina époxi vem sendo muito empregada nas indústrias e em construções para reconstrução de estrutura de concreto, como material para revestimento, anticorrosivo, manutenção de maquinas, e como infinitos modelos de estrutura. A resina epóxidica, tem excelentes propriedades, tais como, resistência aos solventes, estabilidade térmica,

Afiliação dos autores: $\$$ \$ Mestrado Profissional em Materiais do Centro Universitário de Volta Redonda; Centro Universitário Geraldo Di Biase - UGB

$\dagger$ Mestrado Profissional em Materiais do Centro Universitário de Volta Redonda - UniFOA

*Email para correspondencia: ricardo.cabral@foa.org.br 
resistência em altas temperaturas, boa adesão, boa isolação térmica, entre outras (Amaral, Barra, Barcia, \& Soares, 2001) e (Singla \& Chawla, 2010).

Hoje ocupam o posto de um dos mais importantes polímeros termorrígidos, como adesivos/agentes de união e aplicado em outras estruturas como reforço. É um material com boa resistência ao impacto, térmica e química, porém apresenta uma baixa resistência a fratura, o que é sua maior deficiência. A polaridade das hidroxilas alifáticas e dos grupamentos éteres que, constantemente, montam a cadeia da resina, e a rede do sistema após polimerização, fazem com que essas resinas apresentem uma alta adesão. Por conta da polaridade destes grupos criam-se forças atrativas a molécula epoxídica em si e a superfície na qual é aplicada, por isso sua utilização como revestimento, adesivo, como matriz de compósitos (Pires, Pereira, Dias Filho, \& Vecchia, 2005).

De acordo com Singla et al. (2010), as resinas epóxi são materiais comumente utilizados como matriz para materiais compósitos de plásticos termorrígidos. As resinas epóxi pertencem a uma família de plásticos termorrígidos que não liberam produtos de reação durante a sua moldagem e possuem baixa contração durante o seu processamento.

Estes fatos dão destaque para a resina epoxídica sobre as demais resinas termofixas, e acabam justificando sua aplicação difundida. Por este motivo foi realizado este trabalho, com intuito de avaliar algumas propriedades deste polímero.

O objetivo desta pesquisa foi o de caracterizar corpos de prova de resina epóxi para a caracterização mecânica, por meio dos ensaios de flexão, tração e dureza Shore D, morfológico, por meio da análises de Microscopia Eletrônica de Varredura (MEV) e de microscopia de luz e térmicos, pelas análises de Calorimetria Exploratória Diferencial (DSC) e Análise de Termogravimetrica (TGA). E desta forma, verificar a viabilidade do uso desta resina para as suas aplicações nas áreas de construção civil e também para confecção de moldes e matrizes.

\section{Materiais e métodos}

Os ensaios foram realizados em um sistema de resina epoxídica fabricado pela empresa Redelease, combinando a resina SQ2001 e um endurecedor SQ3140, que na forma como recebido, se apresenta como um líquido viscoso, cuja temperatura de manipulação fica entre $20-30{ }^{\circ} \mathrm{C}$ e o seu tempo de endurecimento é de 5 à $12 \mathrm{~h}$.

Foram preparadas duas amostras da resina epóxi para análises, a partir do corte de um pedaço retangular de $2 \mathrm{~cm} \times 1 \mathrm{~cm}$, que foram embutidas a frio em uma resina para possibilitar a análise com microscópio de luz e MEV. Para a análise no MEV, a amostra foi metalizada, em ouro a fim melhorar a condutividade. Para isso utilizou-se o equipamento K550X EMITECH Gold, por 30s de deposição.

Durante a simulação de tração identificou-se o estiramento percentual, para isso foram fabricados 3 (três) corpos de prova do tipo I, conforme norma Standard Method for Tensile Properties of Plastic of American Standard for Testing Materials (ASTM, D638-02a) fabricados a partir da resina epóxi descrita acima com 3,00 mm de espessura.

Para uso nasimulação de flexão,confeccionaramse 2 (dois) corpos de prova do tipo I com espessura de $6,00 \mathrm{~mm}$. A geometria dos corpos de prova também foi feita seguindo a norma ASTM D638-02a.

A dureza da resina epóxi foi obtida antes dos ensaios de tração, e foram realizadas nos mesmos corpos de prova. Foram realizadas cinco medições de Dureza Shore D, que é usada para plásticos em geral, sobre os três corpos de prova. Após as medições, foi realizado o cálculo da média dos valores, podendo isto ser visualizado na Tabela 3. Também foi calculada a média e o desvia padrão dos valores.

Os corpos de prova (CP1, CP2 e CP3) foram submetidos a carga de tensão até o rompimento, e um gráfico com a curva de carga $\mathrm{x}$ deformação foi obtido para cada corpo de ensaio (Figura 1). A tensão para cada corpo de ensaio foi calculada através da Equação 1:

$$
\sigma=\frac{P}{A}
$$

Onde:

$\sigma=$ é a tensão em Mega Pascal (MPa);

$\mathrm{P}=$ é a carga de tração em Newton $(\mathrm{N})$;

$\mathrm{A}=$ é a área inicial da segmentação do corpo de ensaio, em $\mathrm{mm}^{2}$;

O estiramento percentual do polímero do qual foi confeccionado os corpos de prova foi estipulado pela Equação2:

$$
A=\left[\frac{\left(L_{R}-L_{O}\right)}{L_{O}}\right] \times 100 \%
$$


Onde:

$\mathrm{A}=$ é o estiramento do polímero em \%;

$\mathrm{L}_{0}=$ é a dimensão inicial longitudinal do corpo de ensaio medido antes do ensaio de tração, em mm;

$\mathrm{L}_{\mathrm{R}}=$ é a dimensão do comprimentodo corpo de ensaio medido após ruptura, em $\mathrm{mm}$;

As propriedades térmicas da resina foram obtidas a partir das técnicas de Differential Scanning Calorimetry (DSC) e ThermogravimetricAnalysis (TGA), utilizando um forno para degradação do material. Neste forno, uma amostra é aquecida sobre uma balança e de acordo com o aumento de temperatura, sua massa é determinada. Uma atmosfera inerte é criada no interior do forno, de modo que o material não sofra reação química com o oxigênio presente no ar externo.

A massa da amostra diminui com o aumento da temperatura e os dados de massa residuais e fluxos termais, são gerados pelo equipamento em função da temperatura.

Os ensaios de flexão e tração foram executados em um equipamento EMIC modelo DL10000, com capacidade máxima de $100 \mathrm{kN}$. As duas extremidades dos corpos de prova foram fixadas nas garras do equipamento e a velocidade de alongamento foi ajustada para $5,00 \mathrm{~mm} / \mathrm{min}$ até a ruptura para realizar o ensaio de tração e determinação do alongamento percentual. A medição do alongamento dos corpos de prova foi medida pelo próprio equipamento no momentodo ensaio de tração.

Aestipulação da dureza foi feita atravésde um durômetro do modelo Shore D 400.140 fabricado pela Digimess.

As amostras de resina epóxi foram embutidas e metalizadas para serem submetidas ao teste de microscopia óptica para análise da microestrutura do

Tabela 1. Medidas iniciais dos corpos de prova para o ensaio de tração e alongamento percentual.

\begin{tabular}{|c|c|c|c|c|c|c|}
\hline & CP1 & & $\mathrm{CP} 2$ & & CP3 & \\
\hline Medida & $\begin{array}{l}\text { Largura } \\
(\mathrm{mm})\end{array}$ & $\begin{array}{l}\text { Espessura } \\
(\mathrm{mm})\end{array}$ & $\begin{array}{l}\text { Largura } \\
(\mathrm{mm})\end{array}$ & $\begin{array}{l}\text { Espessura } \\
(\mathrm{mm})\end{array}$ & $\begin{array}{l}\text { Largura } \\
(\mathrm{mm})\end{array}$ & $\begin{array}{l}\text { Espessura } \\
(\mathrm{mm})\end{array}$ \\
\hline $1^{a}$ & 13,00 & 3,00 & 13,00 & 3,50 & 13,00 & 3,55 \\
\hline $2^{\mathrm{a}}$ & 13,00 & 3,00 & 13,00 & 3,35 & 13,00 & 3,50 \\
\hline Média & 13,00 & 3,00 & 13,00 & 3,43 & 13,00 & 3,53 \\
\hline $\begin{array}{l}\text { Área } \\
\left(\mathrm{mm}^{2}\right)\end{array}$ & 39,00 & & 44,59 & & 45,89 & \\
\hline
\end{tabular}

Tabela 2. Alongamento percentual dos corpos de prova após serem submetidos ao ensaio de tração conforme norma ASTM D638.

\begin{tabular}{|c|c|c|c|c|c|c|}
\hline & $\mathrm{CP} 1$ & & $\mathrm{CP} 2$ & & $\mathrm{CP} 3$ & \\
\hline Medida & $\mathrm{L}_{0}(\mathrm{~mm})$ & $\mathrm{L}_{\mathrm{R}}(\mathrm{mm})$ & $\mathrm{L}_{0}(\mathrm{~mm})$ & $\mathrm{L}_{\mathrm{R}}(\mathrm{mm})$ & $\mathrm{L}_{0}(\mathrm{~mm})$ & $\mathrm{L}_{\mathrm{R}}(\mathrm{mm})$ \\
\hline $1^{a}$ & 50,00 & 54,50 & 52,00 & 56,60 & 53,00 & 57,30 \\
\hline $2^{a}$ & 52,00 & 55,00 & 53,00 & 56,65 & 50,00 & 55,00 \\
\hline Média & 51,00 & 54,75 & 52,50 & 56,58 & 51,50 & 56,15 \\
\hline $\mathrm{A}(\%)$ & 7,35 & & 7,76 & & 9,03 & \\
\hline
\end{tabular}


Tabela 3. Dureza Shore dos corpos de prova utilizados no ensaio de tração.

$$
\text { CP1 }
$$

$\mathrm{CP} 2$

$\mathrm{CP} 3$

\section{Dureza Shore}

Média $\quad 65,78 \pm 4,66 \quad 63,18 \pm 2,08 \quad 59,98 \pm 2,89$

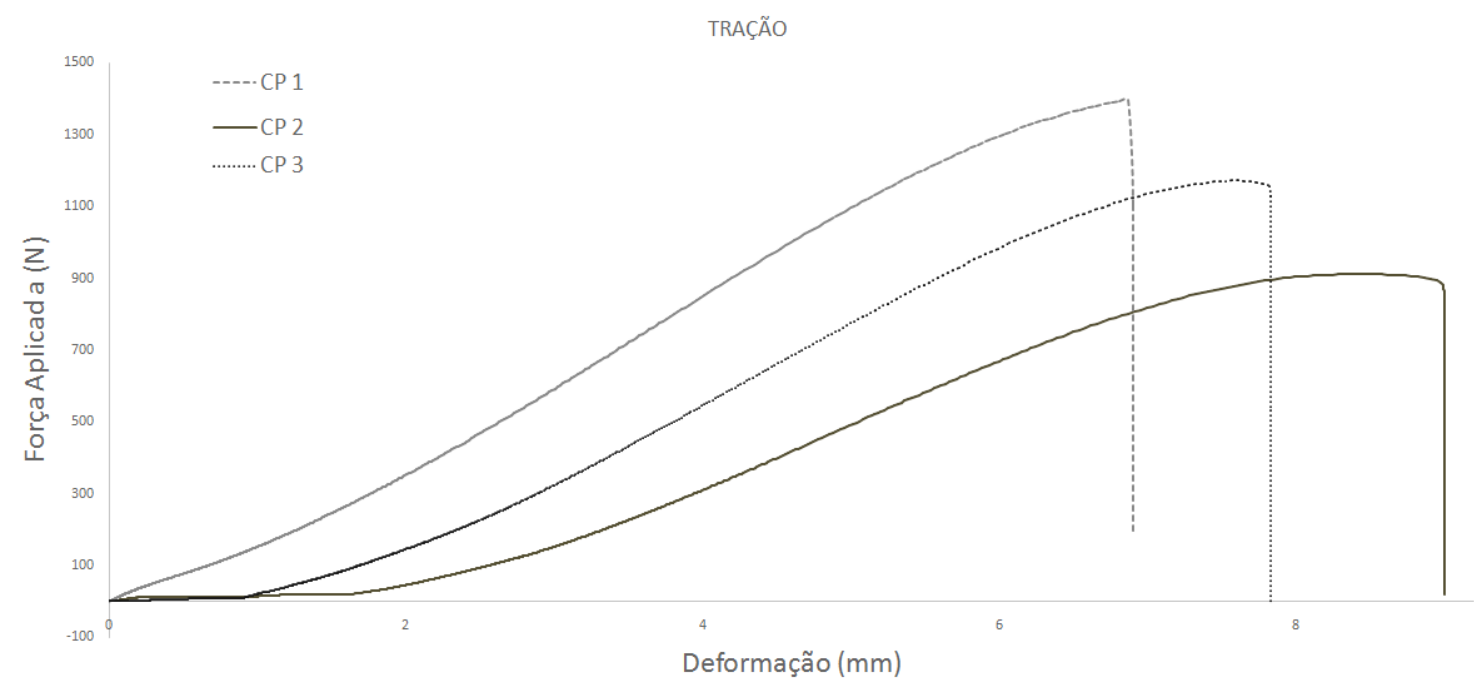

Figura 1. Curva de Tensão-Deformação dos ensaios mecânicos.

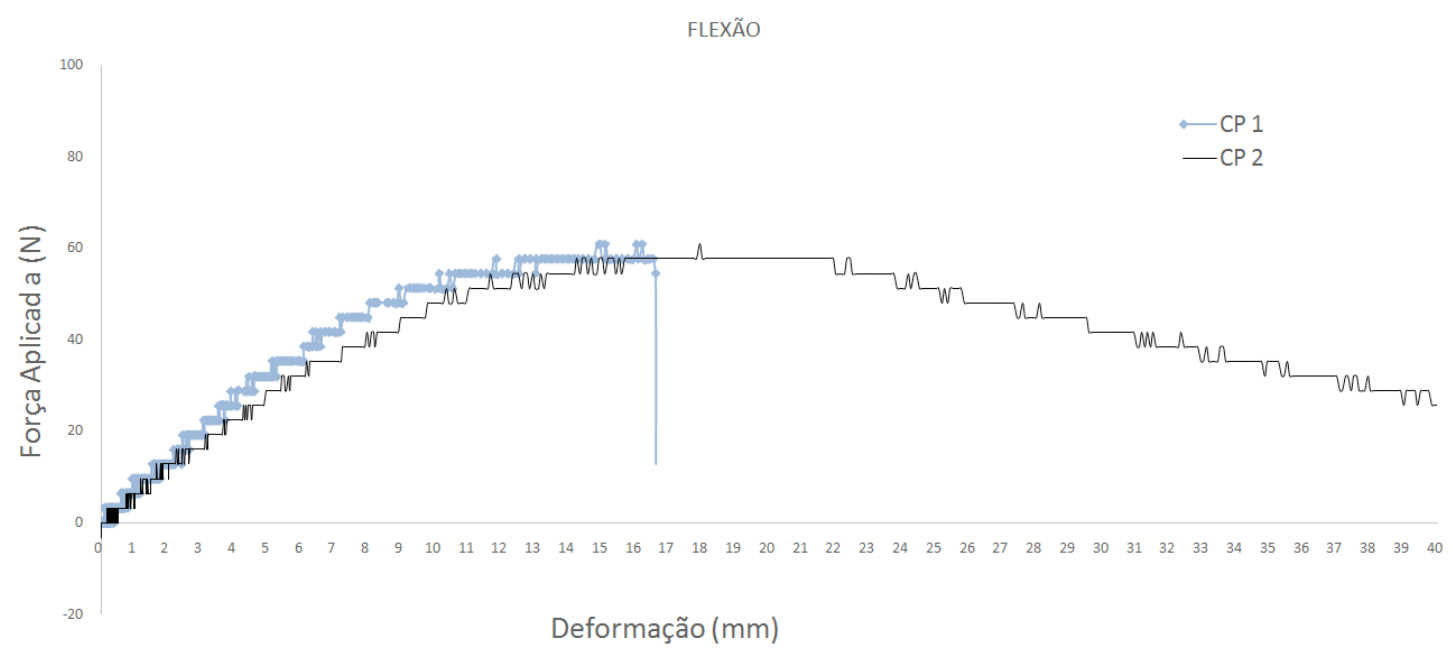

Figura 2. Curva do ensaio de Flexão. 
material.

A análise da microscopia de luz foi realizada em um microscópio da marca Opton, com uma câmera digital DCM35 acoplada ao microscópio.

Para as análises DSC e TGA foi utilizado um forno analisador modelo STA6000 fabricado pela Perkin Elmer, em atmosfera de nitrogênio, com taxa de aquecimento de $10{ }^{\circ} \mathrm{C} / \mathrm{min}$. $\mathrm{O}$ ensaio foi realizado da temperatura ambiente até $580^{\circ} \mathrm{C}$.

\section{Resultados}

Após o ensaio de Dureza Shore D(SD), pode-se afirmar que a resina époxi, pode ser classificada como um polímero duro, pois resistiu à penetração da agulha do durômetro. $\mathrm{O}$ valor médio de durezasdos corpos de prova foi de $62,9 \mathrm{SD}$ com desvio padrão de 2,90 .

Na Tabela 1, constam os resultados obtidos das medidasdo polímero analisado, para simulação de tração, duas medições foram realizadas de largura e espessura $(\mathrm{mm})$, sua média $(\mathrm{mm})$, e área calculada $\left(\mathrm{mm}^{2}\right)$ de acordo com os valores médios das dimensões. A área considerada para estudo é a seção demarcada no corpo de prova.

Os resultados obtidos para o estiramento percentual do material após os ensaios de tração podem ser observados na Tabela 2. A curva de tensãodeformação deste ensaio está representada na Figura 1.

Os valores de tensão máxima do ensaio de tração ficaram bem próximos, sendo $26 \mathrm{MPa}$ o valor médio aproximado da tensão máxima de tração, sendo o desvio padrão de 8,08. O alongamento de cada corpo de prova deste ensaio pode ser observado na Tabela 2.

A média da tensão máxima de flexão foi de 15,68 MPa, a média do módulo de elasticidade foi $288,7 \mathrm{MPa}$, e a média da força máxima observada neste teste foi de $60,84 \mathrm{~N}$. Os dados completos dos ensaios podem ser observados a seguir na Figura 2.

Ao ensaio de flexão a força máxima aplicada atingiu o valor $60,84 \mathrm{~N}$ em ambos os corpos de prova, mas o valor de tensão máxima de flexão divergiu muito pouco, sendo $15,68 \mathrm{MPa}$ o valor médio, com desvio padrão de 0,06 .

Após o ensaio mecânico de tração, a resina epóxi, foi submetida a análise no MEV para verificar a estrutura da secção fraturada (Figura 3). Foram obtidas imagens com ampliação de 200x (Figuras 6a e 6c) e 400x (Figuras 6b e 6d).

Na microscopia óptica (Figura 3) pode-se observar as fibras do material sem deformações ou fratura para uma ampliação de 200x. Também é possível identificar impurezas no material.

Já na análise com microscópio de varredura de elétrons (MEV), foram utilizadas duas ampliações, a saber, de 200X e 400X em uma amostra preparada a partir de um corpo de prova após o rompimento (Figura 4). Nas imagens, podem se identificar as trincas em vários planos com formação do tipo escarpas, além da deformação plástica do material, caracterizando o modo I de falha (Franco, Botelho, Candido \& Rezende, 2009).

Por último foram realizadas as análises térmicas. Pelo gráfico obtido na análise DSC (Figura 5), a temperatura de transição vítrea se dá em $355,60{ }^{\circ} \mathrm{C}$, que é o primeiro ponto de inflexão da curva gerada. Do segundo ponto de inflexão, onde a curva atinge o máximo de fluxo de calor se obtém a temperatura de recristalização, a saber, $445,70{ }^{\circ} \mathrm{C}$.

Por fim, o ponto de fusão da resina é determinado pelo terceiro ponto de inflexão, onde o fluxo de calor passa a aumentar novamente, o que ocorre na temperatura de $479,26^{\circ} \mathrm{C}$.

A análise TGA gerou o gráfico da Figura 6, onde é mostrada a decomposição da massa da resina epóxi em função da temperatura. O ensaio resultou em uma massa residual de $2,54 \%$ da massa original, na temperatura de $580^{\circ} \mathrm{C}$.

A Figura 7 descreve os principais intervalos de perda mássica. No primeiro intervalo, que iniciou com $67,57^{\circ} \mathrm{C}$, a perda foi pequena, e se deve à eliminação de água residual e outros compostos mais voláteis. No segundo intervalo, que se inicia na temperatura de $262,78^{\circ} \mathrm{C}$, a perda é bem mais significativa e é característica de degradação da resina em si.

\section{Discussões}

Pires et al. (2005) afirmam que resinas epóxi apresentam uma baixa resistência a fratura, fato observado no experimento realizado com um alongamento entre 7 e $9 \%$ ao final do ensaio de tração, relativamente pequeno, como mostra a Tabela 2, e tendo um valor médio de $8,05 \%$. Esse fato demonstra que o material não apresenta um comportamento tão dúctil quantos outros polímeros existentes no mercado.

Conforme afirma Pires et al. (2005), as resinas epoxídicas destacam-se das outras resinas termofixas. Sãofeitosinúmeros esforçosparamelhoraro desempenho de inúmeros produtos atuais, usando a resina epóxi como a matriz, para criação de diversos compósitos, para as mais variadas demandas comerciais.

Panzera et al. (2010) realizaram um estudo das propriedades mecânicas de um compósito a base de cimento de Portland e resina epoxídica, afirmando que dependendo da massa específica, o módulo de elasticidade do compósito varia. Os resultados obtidos por Panzera et al. (2010) mostraram variações no seu módulo de Young de 13 a $50 \mathrm{GPa}$, aproximadamente. Valor este, muito acima ao módulo de Young observado neste estudo, o qual apresenta a resina epóxi em sua 


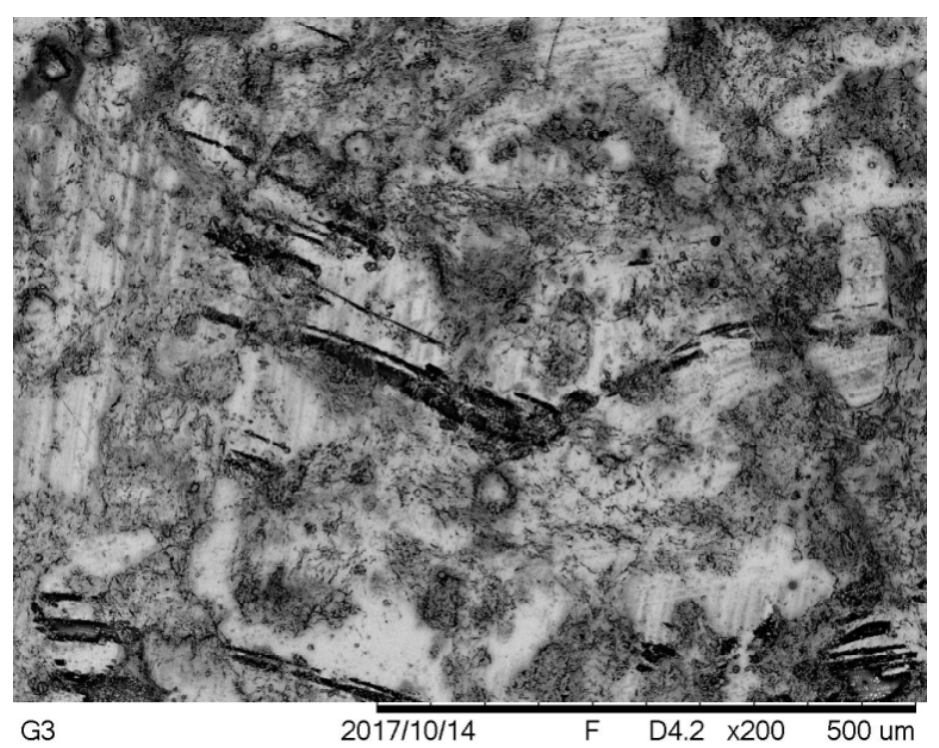

Figura 3. Figura da resina epóxi da microscopia de luz.
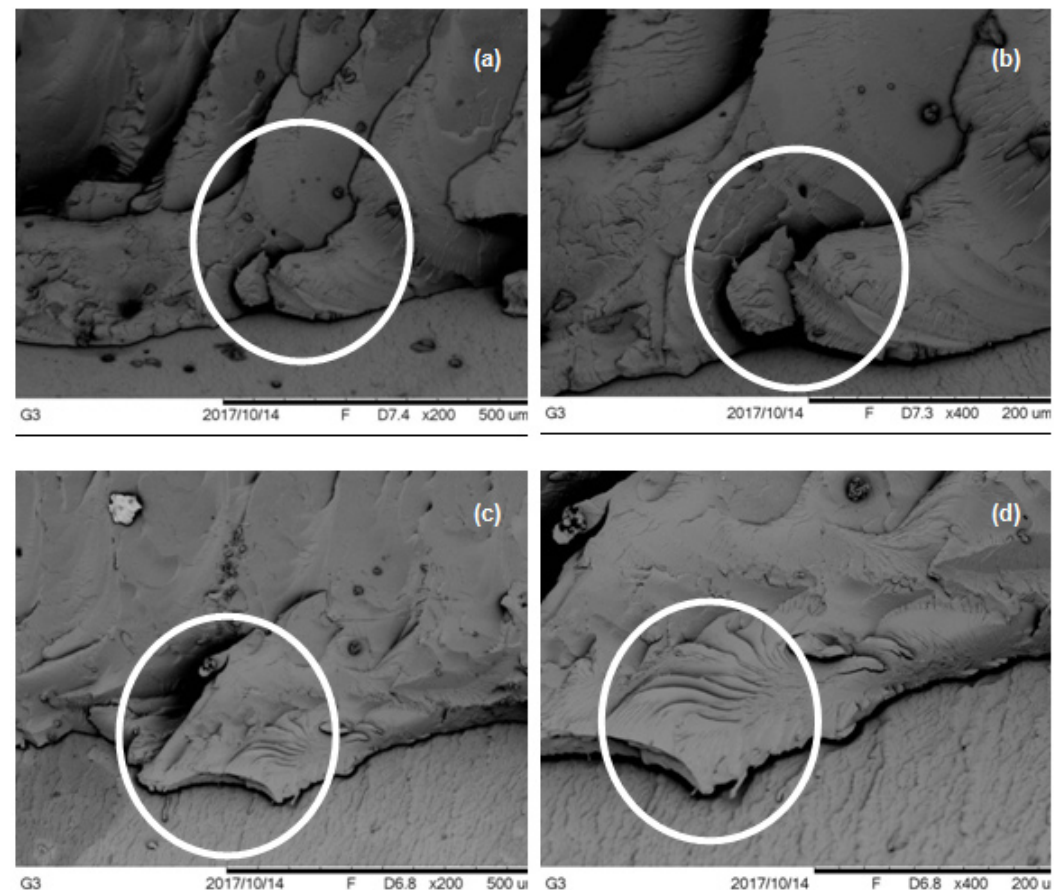

Figura 4. Imagens da Microscopia Eletrônica de Varredura da resina epóxi.

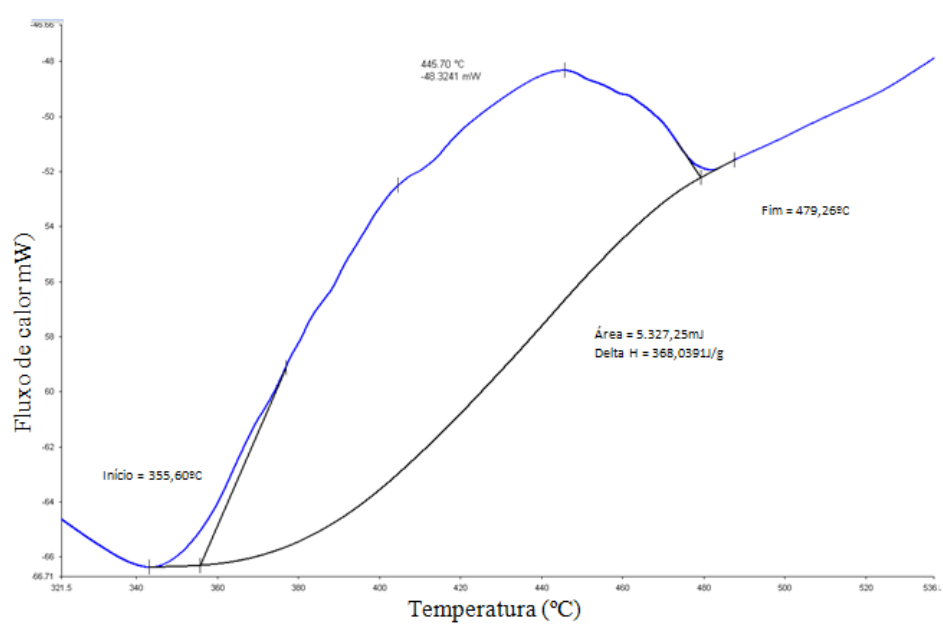

Figura 5. Curva DSC. 


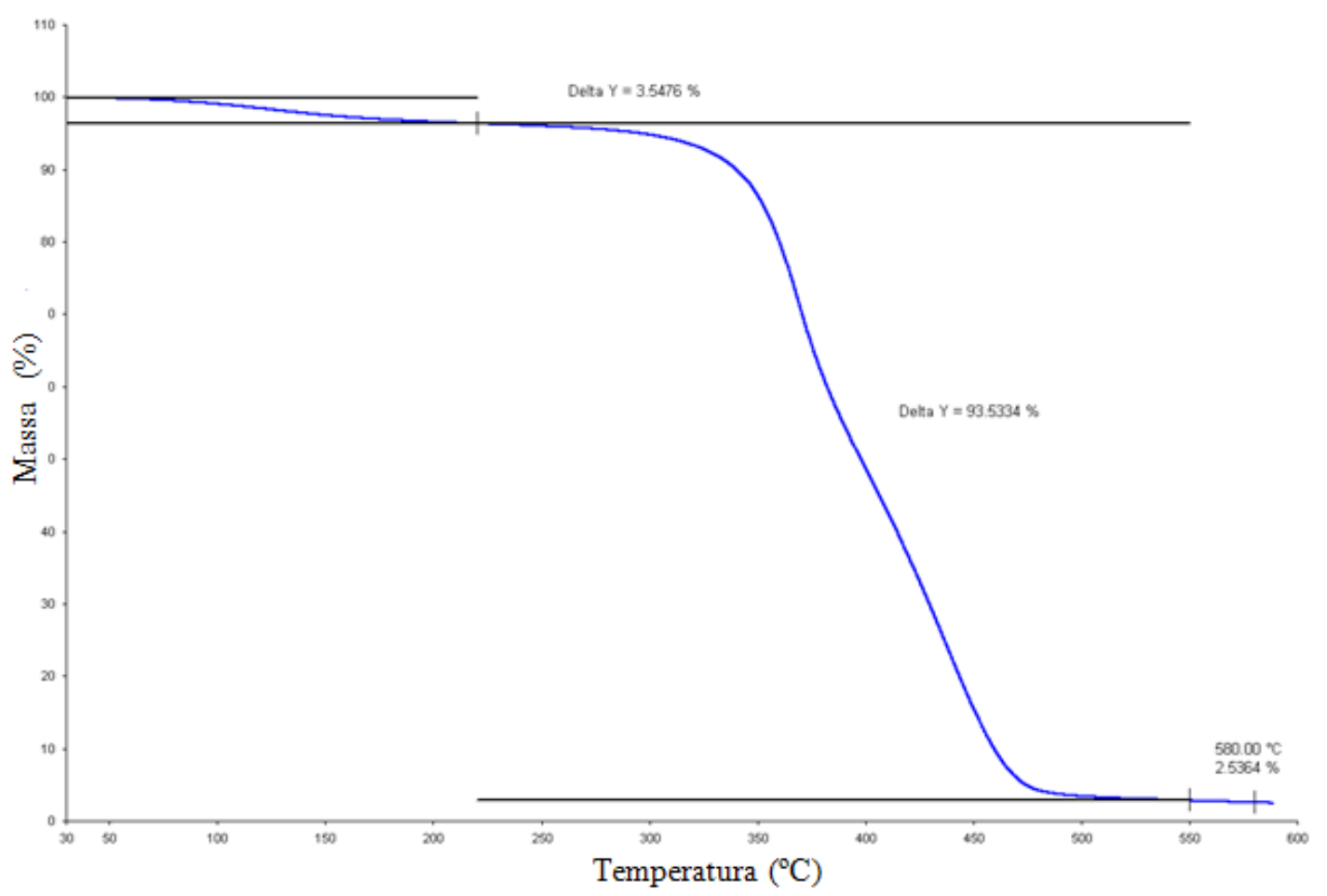

Figura 6. Curva TGA.

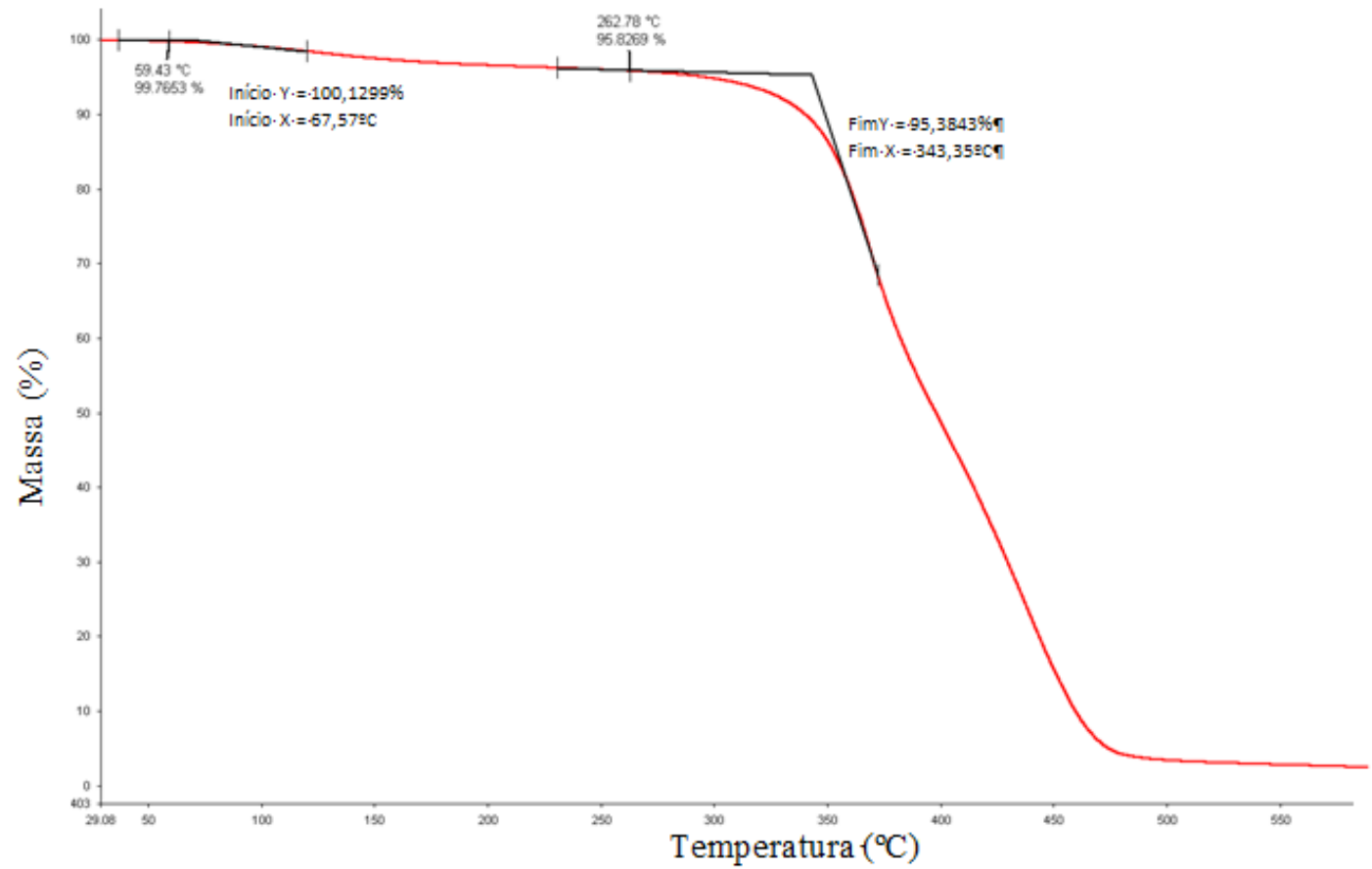

Figura 7. Curva Onset e TI. 
forma pura, sem adição de nenhum outro material, e por este motivo consequentemente apresenta um módulo de Young menor do que o compósito de Portland e Epóxi.

Chantarapanich et al. (2013) determinaram as propriedades de uma resina epóxi variando o tempo de cura, e os resultados do presente teste são comparados a esse ensaio e as propriedades gerais das resinas epóxi, indicando que essas propriedades variam significativamente dependendo da composição e tipo de ensaio. Na sua pesquisa, o módulo de Young foi de 280MPa, o que está de acordo com o que foi obtido no presente estudo, que foi de $288,7 \mathrm{MPa}$.

Campos et al. (2016) utilizando a resina epoxídica SQ 2001, e o endurecedor epicloridrina, na proporção de 100:50, verificaram que o ponto de transição vítrea da resina, encontra-se entorno da temperatura de $75^{\circ} \mathrm{C}$.

Campos et al. (2016), na sua pesquisa indicou que na análise de TGA o início da degradação da resina epóxi, ocorreu na temperatura de $127^{\circ} \mathrm{C}$.

Rocha et al. (2017) em seu trabalho de TGA observaram que a pirólisedo polímero ocorre, dentro de aproximadamente quatro estágios. Primeiramente a partindo da temperatura ambiente até $125^{\circ} \mathrm{C}$, onde acontece um fenômeno endotérmico que pode ser atribuído a perda de água adsorvida na estrutura polimérica, a segunda entre temperaturas de $125^{\circ} \mathrm{C}$ até $295^{\circ} \mathrm{C}$, com uma perda de volume do material por volta de $8 \%$, nesta fase acredita que ocorra uma reorganização estrutural molecular da cadeia polimérica do material, a terceira fase se inicia por volta da temperatura de 295 a $480{ }^{\circ} \mathrm{C}$, aonde a perda de material chega a $52 \%$, o reagente em excesso estequiométrico que foi adicionado a mistura poliéstersiloxano se degrada. A decomposição final do material por pirólise ocorre no intervalo de temperaturas entre 480 a $750{ }^{\circ} \mathrm{C}$.

Rocha et al. (2017) constaram através da análise de TGA uma mínima perda de massa, abaixo de $100^{\circ} \mathrm{C}$, que pode ser associada à presença de moléculas de água absorvidas nos materiais. Entre os materiais analisados, uma das misturas preparadas, demonstrou maior estabilidade térmica, no segundo pico indicando $28 \%$ de perda de massa, na faixa de $350{ }^{\circ} \mathrm{C}$.

\section{Considerações finais}

A análise microscópica da resina epóxi após ruptura por tração mostra claramente as trincas em vários planos que levaram à fratura do material.

As resinas são estáveis em temperaturas de até $250^{\circ} \mathrm{C}$, onde nessa temperatura não sofrem degradação, ou apresentam perda de massa insignificante (se tratando do material puro). Este valor pode aumentar se associado a outro material.

Nos dados obtidos em relação a Dureza Shore, caracterizam a resina epóxi como um polímero duro, pois sua dureza média atinge 62,9 SD.

Apesar de apresentarem elevada dureza, ao se comparar os valores obtidos neste trabalho com outros ensaios da presente pesquisa, foi constatado que as propriedades mecânicas das resinas epóxi apresentam uma linha de oscilação, contudo, podendo ter sua utilização em matrizes para obtenção de compósitos.

\section{Referências}

Amaral, T. P., Barra, G. M. O., Barcia, F. L. \& Soares, B. G. (2001). Estudo das propriedades de compósitos de polianilina e resina epoxídica. Polímeros: Ciência e tecnologia, 11 (3), 149-157.

ASTM, D638-02a, Standard Test Method for Tensile Properties of Plastics. (2002).

Campos, M. C., Soufen,C. A., Sander, C. A., Imaizumi, M. \& Brandino, T. L. S. (2016). Caracterização da degradação superficial da interface reforçoMatriz de materiais compósitos poliméricos. Revista Ciência e Tecnologia, 19 (34).

Chantarapanich, N., Puttawibul, P., Sitthiseripratip, K., Sucharitpwatskul, S. \& Chantaweroad, S. (2013). Study of the mechanical properties of photocured epoxy resin fabricated by stereolithography process. Songklanakarin Journal of Science and Technology, 35 (1), 91-98.

Franco, L. A. L, Botelho, E.C., Candido, G. M.\&Rezende, M. C. (2009). Análise fractográfica do modo de falha de compósitos carbono/epóxi, Matéria, 14 (1) 694-704.

Menezes, C. C. G., Adde, C. A., Utumi, E. R., Pedron, I. G. \& Silva, L. P. N. (2011). Considerações referentes aos processos alérgicos decorrentes do uso do látex em Odontologia, Rev. Odontol. Bras. Central, 20 (55), 304-307.

Morais, F. A. I., Mello, B. A., Souza, I. A., Ponzi, E. A. C. \& Revoredo, G. A. (2007). Polímeros a base de metil metacrilato. Importância em odontologia, International jornal ofdentistry, 6 (2) 63-66.

Panzera, T. H., Sabariz, A. L. R., Strecker, K., Borges, P. H. R., Vasconcelos, D. C. L. \& Wasconcelos, W. L. (2010). Propriedades mecânicas de materiais compósitos à base de cimento Portland e resina epóxi, Cerâmica, 56, 77-82.

Pires, G., Pereira, D. S., Dias Filho, N. L. \& Vecchia, G.D. (2005). Caracterização físico-química e mecânica do sistema éster de Silsexquioxano/ Resina Epóxi Dgeba/Dietilenotriamina. Revista Matéria,10 (2), 317-330.

Rocha, R. J., Rocco, J. A. F. F., Silva de Oliveira, M. A. \& Iha, K. (2017). High layer coating obtained in the reaction of modified novolacepoxys resins with organosiloxanes through acid catalysis. Quimica Nova, 40 (2), 146153.

Singla, M.\& Chawla, V. (2010). Mechanical Properties of Epoxy Resin Fly Ash Composite. Journal of Minerals \& Materials Characterization \& Engineering, 9 (3), 199-210. 